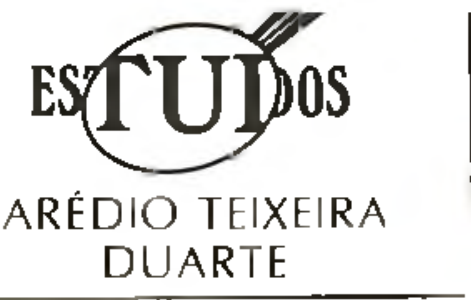

\title{
É fundamental que as decisões do Governo sejam fiscalizadas
}

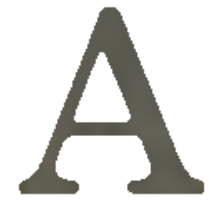

0 ser instalado o governo da Nova República. dentro dos an selos de mudanćca, tornou-se necessária a reallzação de uma reforma administrativa que atenda os Estados e a Naçāo. E como a determinaçāo do Presidente José Sar ney é de se fazer, de fato, uma recorma é imprescindível a açāo conjunta dos órgāos da admínistraçāo federal, que posteriormente atingirá os Estados, evitando-se assim que esta se transforme em apenas mals uma reforma. Esta integracâo forte entre todos os envolvidos é fundamental para que tal reforma tenha prosseguimento nos futuros governos, coibindo-se assim que a reforma proposta termine antes que os resultados aparecam, a exemplo do que aconteceu em governos anteriores. As propostas e programas desta meta devem estar voltados para que a administracāo púhllca seja dotada de conceitos que resultem em aumento da pro dutividade, reducào de custos operacionais e agilizaçāo de resultados.

E para que o Governo da Nova Repúhlica possa atender as promessas e compromissos éticos, será necessário instalar um novo modelo de Administraçāo Pública, tendo como princípios básicos a restauraçāo da cidadania, a democratizaçāo, a descentraliaçāo e a reoríentaçāo do Serviço Público.

Para se restaurar a cidadania, ou seja, prover os cidadāos de méos para a realização dos seus direitos. obedecendo aos critérios de universalidade e acesso Irrestrito, o Estado deverá fornecer-lhes informacōes, colocando as decisōes próximas ao cldadāo e atribuindo-lhe a

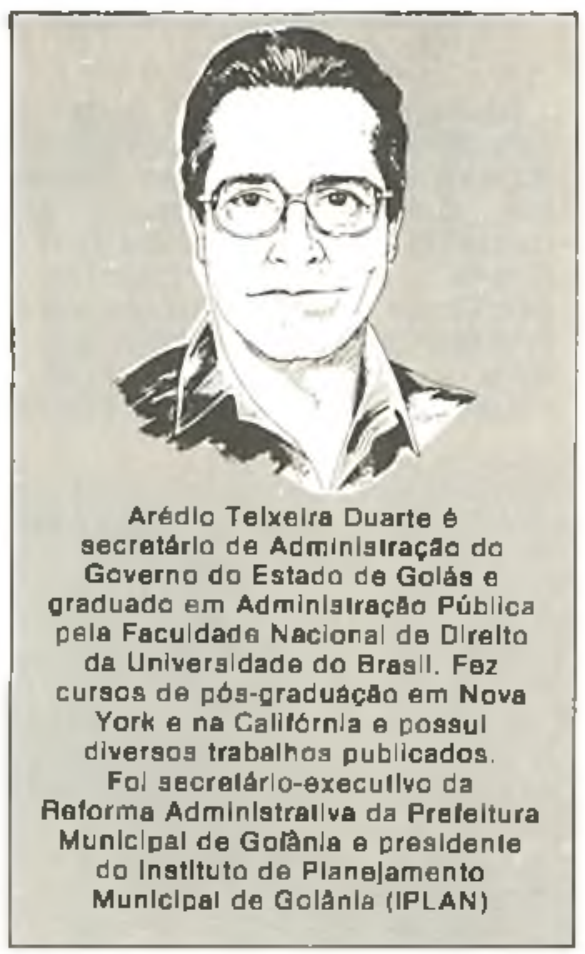

capacidade de controle e reclamacāo. Para tanto será necessária a reorientaçāo e a melhoria dos serviços públlcos essenciais

Outro item de fundamental importância é a democratlzaçāo da açào administrativa em todos os niveis de Governo, onde, após amplos debates e decisães democráticas, os resultados Incorporem posiçōes dos diversos segmentos da socledade. Isto, além de se promover uma dinamizaçāo das açoes, o controle do Poder Executivo pelo Poder leglslativo e pela sociedade, a articulaçāo e proposiçāo de novas modalidades organizacionais de declsāo, e a execuçāo e controle administratıvo e institucional.

A reforma administrativa que está sendo elaborada deverá, tam- bém, dar atençảo especial para a descentralizaçāo e desconcentraçāo da açāo administrativa, com o objetivo de restabelecer 0 federallsmo e de situar a decisāo pública próxlma do local de açāo. Tal prática será acelerada mediante um exame e debate sobre as funcōes que a sociedade deseja exercidas em cada nivel de Governo. Os mecanismos fiscais e financeiros de alocaçāo de recursos tamhém devem ser revistos.

Motivar e engajar o servidor e valorizá-lo é imprescindivel para o bom andamento da administraçāo pública. e. para tanto. será necessário consolidar as muitas práticas de adminlstraçāo de pessoal em uma politica mals coerente; estabelecer critérlos de ingresso, progresso, trelnamento, remuneraçāo e benefícios adequados à execucào descentralizada, respeitadas as diversidades setorlals; huscar a descompressão salarial imposta a todos os nivels do Serviço Público; estimular, na administraçāo pública rederal, estilos gerencials que promovam a melhoria da qualidade de seus bens e serviços, a produtividade e a realizaçāo prfissional de seus servidores.

A alocaçāo mais eficiente de recursos é essencial para a melhoria dos padrōes de desempenho da administraçāo e, para tanto, torna-se necessárjo reduzir o desperdício em muitos setores e funçōes governamentais; equilibrar a composiçāo dos gastos, assegurando a reduçào do díspêndio com a própria adminıstraçāo em favor da utilizaçāo dos recursos na provisāo efetiva de bens e servicos: reverter o processo de crescimento desordenado da administraçāo federal; slmplificar e desburocratizar os procedimentos; 
evitar a Imposiçāo de estruturas, normas e procedimentos idênticos para órgăos e entidades de nature2a distintas.

No âmbito desta reforma, devese dar atencāo especial para as adminıstraçōes estaduais dentro dos objetivos básicos de descentralizaçāo e desburocratizaçāo, uma vez que somente uma administra cão pautada em normas especiflcas para cada regiao, considerando-se obviamente os padrōes nacionaís. surtírá os eleitos propostos.

A centralizacāo, além de ser um componente geopolítíco histórico. herdado da colonizaçāo portuguesa, vem sendo alimentada por uma combinaçāo espúria dos condicionamentos culturais e pela motiva çāo de poder do processo burocrático A centralizaçāo se dá de duas formas: pela ampliaçăo do setor público e pela captura dos níveis estaduais e municipals, através da induçāo normatıva, organizacional e utilitária. Diante disto, cabe á reforma a reversāo das forças centralizadoras, pela reduçāo do dominio do setor público sobre o setor privado e pela transferéncia de competências, funcōes e atribuicōes da Uniajo para os Estados e Muricipios. E como isto se daria? Através da elahoraçāo de matrizes de órgāos e entidades federais para identilicaçāo de superposiçōes competitivas e redundantes e aplicaçāo dos critérios de descentralizaçāo; e a identificaçāo, junto aos Estados e organizacōes municipais, da capacidades de absorçăo seletlva das luncōes e atividades descentralizavejs.

A burocratizaçāo é outro fator emperrante para o bom runcionamento da máquina administrativa. A burocrátlzaçāo é um corolárlo natural da indexaça burocrática da sociedade civll. E. enquanto nāo forem desmontados os mecanismos indexadores, dificilmente serāo eliminados os procedimentos perpetuantes da dependência individual e grupal ao aparelho estatal. E para se corrigır estas distorçōes, deve-se partir para açōes que visam elimiлаг a causa central identificada em um diagnóstico. A elimInaçăo de estruturas (indexantes" dará partida ao processo de eliminaçāo de exigências, já que, cessada a causa, cessa o efejto. para tanto, serāo necessárias açōes como a identiff caçāo, através de uma curva ABC. das áreas onde há major burocrati- zaçāo concentrada e proposiçāo de medidas concretas de simplificaçāo. A identílicaçāo de medidas adotadas pelo Ministério da Desburocratizaçāo e que foram anuladas pelos hábitos burocratizantes, avallando resultados e valjdade de revigorá-las é também uma acão que deve ser encampada por qualquer governo que se propōe fazer uma reforma administrativa. Devese também promover a Identifica cāo de práticas de aquisiçào de ma terlais que dificultam as relaçōes dos fornecedores com o Governo.

E fundamental também que as administracōes estaduais tenham autonomla em suas açoes e que, ao mesmo tempo, desenvolvam junta mente com os demais Estados, um tratamento untário de problemas administrativos, especialmente os referentes aos assuntos da área de recursos humanos

Para que os Estados possam realmente encampar a proposta do governo da Nova República e para que a reforma administrativa re sulte em aumento de produtivida de, reduçāo de custos operacionals e agllizaçāo de resultados, torna-se primordial, em uma primeira instáncia, a efetivaçāo de dois mecanismos básicos: a reforma tributa ria e a críaçāo de um instrumento ligando os Estados diretamente ao Governo Federal.

Somente a partir de uma reforma tributária, os Estados e Municípios passarāo a ter maior autonomla administrativa e, conseqüentemente, maior geraçāo de recursos. Sem que o Governo Federal efetlve, a níveis satisfatórios, a reforma tributária, a propesta de reforma administrativa cairá no descrédito. com soluçōes estritamente no âm blto da técnica gerencial, com au- sência de estratéglas e de instrumentos operacionais destinados a facilitar um complexo processo de mudanca soclal, política e cultural.

Açōes Integradas das administracōes estaduais com o Governo $\mathrm{Fe}$ deral, no plano adminjstrativo, é de fundamental importância. Neste caso, é imprescindivel a instltuiçāo de um orgāo pelo qual se estabeleça uma perfeita conexāo entre as administraçoes estaduais e o Governo Federal. Tratar-se-ia, no caso. da implementaçāo de um Conselho de Administracāo junto ao Ministério da Administraçāo, formado pelos Secretários de Administraçāo dos Estados e presidido pelo Ministro da Administracăo. Tal Idéla. aliás, fol amplamente discutida pelos Secretários de Administracāo dos Estados quando, antes da instalaçāo da Nova República, sugerıram a criaçāo do Ministérjo da Administração.

O Conselho de Administraçāo teria as seguintes funçōes:

- captar, junto ao Governo Federal, as normas gerais aplicávels em todos os Estados da Federaçāo procedendo a sua implementaçāo na órbita de sua jurisdiçāo

- levar ao Ministério os proble mas administrativas dos respectivos Estados, procedendo-se a troca de inlormaçóes entre si e entre os Estados e a Governo Federa];

- constituir-se em instrumento de unlformizaçāo de orjentaçōes unlversais, aplicáveis a todas as órbltas de governo, em decorrêncla da troca de Informaçōes em assuntos de recursos humanos, transporte, material e patrimônio, desburocratizaçāo, entre outros que integram - conjunto de variáveis que permeiam a administraçào pública.

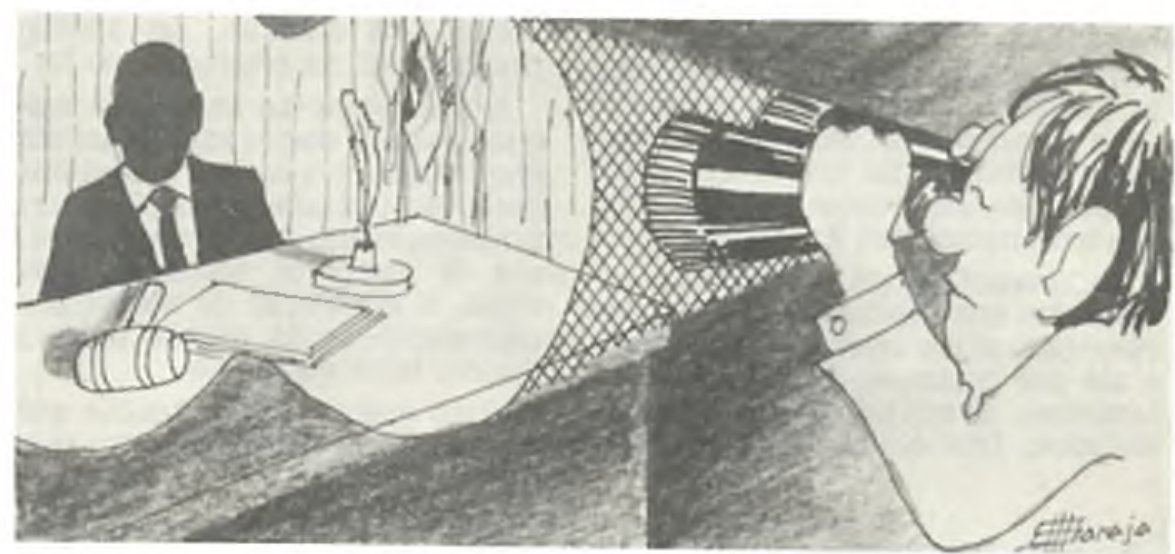

